This item was submitted to Loughborough's Research Repository by the author.

Items in Figshare are protected by copyright, with all rights reserved, unless otherwise indicated.

\title{
A clarion call for aeolian research to engage with global land degradation and climate change
}

PLEASE CITE THE PUBLISHED VERSION

https://doi.org/10.1016/j.aeolia.2018.02.007

PUBLISHER

(C) Elsevier

VERSION

AM (Accepted Manuscript)

\section{PUBLISHER STATEMENT}

This work is made available according to the conditions of the Creative Commons Attribution-NonCommercialNoDerivatives 4.0 International (CC BY-NC-ND 4.0) licence. Full details of this licence are available at: https://creativecommons.org/licenses/by-nc-nd/4.0/

\section{LICENCE}

CC BY-NC-ND 4.0

\section{REPOSITORY RECORD}

Chappell, Adrian, Jeffrey A. Lee, Matthew Baddock, Thomas E. Gill, Jeffrey E. Herrick, John Leys, Beatrice Marticorena, et al.. 2019. "A Clarion Call for Aeolian Research to Engage with Global Land Degradation and Climate Change". figshare. https://hdl.handle.net/2134/32626. 


\section{A clarion call for aeolian research to engage with global land degradation and climate change}

Adrian Chappell ${ }^{1}$, Jeffrey A. Lee ${ }^{2}$, Matthew Baddock ${ }^{3}$, Thomas E. Gill ${ }^{4}$, Jeffrey E. Herrick $^{5}$, John F. Leys ${ }^{6}$, Beatrice Marticorena ${ }^{7}$, Lynda Petherick ${ }^{8}$, Kerstin Schepanski ${ }^{9}$, John Tatarko ${ }^{10}$, Matt Telfer ${ }^{11}$, Nicholas P. Webb ${ }^{12}$.

${ }^{1}$ School of Earth and Ocean Sciences, Cardiff University, Cardiff CF10 3AT, UK

${ }^{2}$ Department of Geosciences, Texas Tech University, Texas, USA

${ }^{3}$ Department of Geography, Loughborough University, Leicestershire, UK

${ }^{4}$ Department of Geological Sciences, University of Texas, El Paso, TX, USA

${ }^{5}$ USDA-ARS Jornada Research Unit, Las Cruces, NM, USA

${ }^{6}$ Science Division, NSW Office of Environment \& Heritage, PO Box 20, Gunnedah, NSW 2380, Australia

${ }^{7}$ Laboratoire Interuniversitaire des Systèmes Atmosphériques, Université Paris Est Créteil, Paris, France

${ }^{8}$ Department of Geography, University of Victoria, New Zealand

${ }^{9}$ Leibniz Institute for Tropospheric Research, Leipzig, Germany

${ }^{10}$ USDA-ARS Rangeland Resources and Systems Research Unit, Fort Collins, CO 80526, USA

${ }^{11}$ School of Geography, Earth and Environmental Sciences, Plymouth University, Plymouth PL4 8AA, UK

${ }^{12}$ USDA-ARS Jornada Experimental Range, Las Cruces, NM, USA

This editorial represents a clarion call for the aeolian research community to provide increased scientific input to the Intergovernmental Panel on Climate Change (IPCC) and the United Nations Convention to Combat Desertification (UNCCD) and an invitation to apply for ISAR funding to organize a working group to support this engagement.

This journal, Aeolian Research, represents the work of the community in the international society of the same name (ISAR) and is the forum of the International Conference on Aeolian Research (ICAR). The presentation of research at ICAR III (Zzyzx, California, USA, 1994) acted as the catalyst for the emergence of ISAR and the journal. In the early days of ICAR, most work presented was divided between studies of aeolian transport mechanisms, and coastal and continental dune dynamics. The number of papers reporting single-dune studies declined and were 
replaced by interest in dust entrainment and transport and in palaeo-environmental studies (Livingstone et al., 2007; Stout et al., 2009). The papers culminating in the book (Shao, 2000) on the physics and modelling of wind erosion, and the paper by Marticorena and Bergametti (1995), are key markers of the emerging dominance of dust as a focus of the research community. One of the first reviews in this journal was on the dust cycle and its importance in Earth systems (Shao et al., 2011). Concomitantly, a minority of researchers in the community focussed their contributions to ICAR on desertification and land degradation via wind erosion. With growing recognition of the importance of addressing land degradation for climate change mitigation and adaptation effectiveness, and increased connections between the IPCC and UNCCD, there now appears to be an opportunity for this minority focus to predominate.

The aeolian research community has amongst other things, influenced the development of dust emission modelling (global and regional; GDEMs) to quantify and describe the material emitted to the atmosphere and to represent the interactions within global climate models (GCMs). However, these developments have not been embedded in land surface models (LSMs); the loss of soil organic carbon (SOC) and nutrients and their dynamic feedbacks and interactions with biogeochemical and biophysical cycles are omitted (Chappell et al., 2015). Consequently, the scientific community has created a paradox in which dust is produced for the GCM but wind erosion and dust emission are omitted in the LSM. These omissions beg questions about fidelity of climate change impacts projections, and hence the ability to interpret future change in agroecological systems particularly in drylands (e.g., Ahlstrom et al., 2015). Of perhaps greater significance to the aeolian research community, is that the omission of wind erosion and dust emission from LSMs deprives the scientific community of a tool to readily demonstrate climate change impact that is currently largely unacknowledged, and to contribute to management and policy options of global importance, like future food security.

The publication profiles of many established researchers in the aeolian research community are testimony to the agility with which they have redirected their foci, perhaps led by research funding. An opportunity is emerging for the aeolian research community to focus on wind erosion and engage with the "...science-based synergistic potential of sustainable land management (SLM) practices to address DLDD [desertification, land degradation and drought], climate change mitigation and adaptation" (UNCCD, 2015b; p.8). At its 45th session (March 2017), the IPCC agreed to a Special Report on climate change, desertification, land degradation, sustainable land management, food security, and greenhouse gas fluxes in terrestrial ecosystems. Aeolian processes affect each of these impact areas and, if it is willing to engage, our research community could achieve greater integration of our science across the UN conventions in support of the Sustainable Development Goals (SDGs). 
Our aim here is to raise awareness of that opportunity, to encourage the community to position itself for this foreseeable future of aeolian research, and to ultimately promote more cross-cutting research with impact and ideally for continued high quality papers to be published in this journal. The objective is therefore to encourage researchers, stakeholders, and particularly national research councils to respond with dexterity and urgency to engage with this opportunity. The following section describes the context, timeliness of and need for wind erosion research within this context and outlines the opportunities for engagement. The combined Boards of this journal's Associate Editors and current members of ISAR and other key ex officio members have agreed to fund from ISAR, the travel and expenses of a working group to meet and discuss this opportunity and develop a research publication strategy. This editorial is therefore a call for funding applications to host a workshop (with templates available on the ISAR website and a submission deadline of 1 June 2018).

\section{Renewed agility to engage with wind erosion research}

The forthcoming IPCC special report (planned for September 2019) will assess literature relevant to climate change, desertification, land degradation, sustainable land management, food security, and greenhouse gas fluxes in terrestrial ecosystems, especially since the Fifth Assessment Report (AR5). The report outline is for seven chapters including (Ch2) climate-land interactions, (Ch6) Interlinkages between desertification, land degradation, food security and greenhouse gas (GHG) fluxes: Synergies, trade-offs and Integrated Response Options, and three sections of particular relevance:

- Desertification feedbacks to climate, including sand and dust storms.

- Observed and projected impacts of desertification on natural and human systems in a changing climate. This could include the role of aerosols and dust, impacts on ecosystem services (e.g. water, soil and soil carbon and biodiversity) and impacts on socio-ecological systems (e.g. impacts on vulnerable communities, poverty, food security, livelihoods, and migration).

- Linkages and feedbacks between land degradation and climate change, including extremes (e.g. floods and droughts), erosion, and their effects on ecosystems and livelihoods.

It appears from the list of authors and reviewers of the Special Report for the IPCC that our aeolian research community has not yet engaged with this opportunity. Similarly, for the Global Assessment of Sand and Dust Storms (UNEP, 2016) only a few of our community contributed or acted as reviewers. Nevertheless, in the shortterm (1-2 years) opportunities remain to carefully review, summarise, or describe the significance of wind erosion and dust emission for Earth's systems and particularly land degradation. In the medium-term (3-5 years), opportunities exist for research with support from funding agencies, to demonstrate the impact of wind erosion and 
dust emission on land degradation and particularly with a focus on the simultaneous influences of climate change (Webb et al., 2017). The systematic nature of the review processes virtually ensures that input provided will be considered carefully by the authors of the UN reports.

Another opportunity is through the UNCCD. In 2015, its Conference of the Parties (COP) decided to establish a Science-Policy Interface (SPI) to facilitate a two-way science-policy dialogue and ensure the delivery of policy-relevant information, knowledge and advice on desertification/land degradation and drought (DLDD; Decision 23/COP.11). In other decisions, the COP decided to focus attention on SDG target 15, which includes the intention to "combat desertification, restore degraded land and soil, including land affected by desertification, drought and floods, and (15.3) strive to achieve a land degradation-neutral world" by 2030 (UNGA, 2015). The UNCCD defines land degradation neutrality (LDN) as "a state whereby the amount and quality of land resources necessary to support ecosystem functions and services and enhance food security remain stable or increase within specified temporal and spatial scales and ecosystems" (decision 3/COP.12, UNCCD, 2015a). Three indicators representing the key attributes of LDN have been adopted by the UNCCD: physical land cover, land productivity and SOC (Cowie et al., 2018). These indicators are intentionally complementary, representing different features of the system. Land cover is a highly responsive measure, representing land use dynamics, that reveals change in vegetative cover such as through land conversion and resulting habitat fragmentation. Land productivity (net primary productivity) captures relatively fast changes in ecosystem function. The SOC reflects slower changes resulting from the net effects of biomass growth and disturbance/removal and is an indicator of resilience.

\section{Conclusion}

Existing research indicates that soil erosion should be emphasised in the IPCC report, and that it should be considered as a dominant pressure on the state and quality of land resources. Wind erosion and particularly dust emission, remove selectively SOC and nutrients and transport them rapidly over large distances. Immediately after most land cover changes soil erosion accelerates, causing SOC and nutrients to decline rapidly - impacting the dust aerosol burden and climate, but also critically reducing land potential to support agricultural production and ecosystem services that society depends on. With concerted effort and renewed agility by the aeolian research community, wind erosion and dust emission could become more broadly considered and addressed by the UNCCD, and the IPCC. Consequently, awareness would increase of the significance for wind erosion and dust emission and develop an increased and sustainable basis of environmental funding.

\section{References}


Ahlstrom, A., M.R. Raupach, G. Schurgers, B. Smith, A. Arneth, M. Jung, M.

Reichstein, J.G. Canadell, P. Friedlingstein, A.K. Jain, E. Kato, B. Poulter, S. Sitch, B.D. Stocker, N. Viovy, Y.P. Wang, A. Wiltshire, S. Zaehle, N. Zeng (2015) The dominant role of semi-arid ecosystems in the trend and variability of the land CO2 sink. Science, 348, 895-899.

Cowie, A.L., B.J. Orr, V.M. Castillo Sanchez, P. Chasek, N.D. Crossman, A. Erlewein, G. Louwagie, M. Maron, G.I. Metternicht, S. Minelli, A.E. Tengberg, S. Walter, S. Welton (2018) Land in balance: The scientific conceptual framework for Land Degradation Neutrality. Environ. Sci. Policy, 79, 25-35.

Chappell, A., J. Baldock, J. Sanderman (2015) The global significance of omitting soil erosion from soil organic carbon cycling models. Nat. Climate Change, 10.1038/nclimate2829

Livingstone, I., G.F.S. Wiggs, C.M. Weaver (2007) Geomorphology of desert sand dunes: a review of recent progress. Earth Sci. Rev., 80, 239-257.

Marticorena, B., G. Bergametti (1995) Modeling the atmospheric dust cycle: 1.

Design of a soil-derived dust emission scheme. J. Geophys. Res., 100, 16415-16430.

United Nations General Assembly (2015) Transforming Our World: the 2030 Agenda for Sustainable Development. Resolution adopted by the General Assembly on 25 September 2015.

Webb, N.P, N.A. Marshall, L.C. Stringer, M.S. Reed, A. Chappell, J.E. Herrick (2017) Land degradation and climate change: building climate resilience in agriculture. Front. Ecol. Environ., 15 (8), 450-459, 10.1002/fee.1530. 